Article

\title{
Carapanolides T-X from Carapa guianensis (Andiroba) Seeds
}

\author{
Teppei Miyake ${ }^{1}$, Sari Ishimoto ${ }^{1}$, Naoko Ishimatsu ${ }^{1}$, Keiichiro Higuchi ${ }^{1}$, Katsuhiko Minoura ${ }^{1}$, \\ Takashi Kikuchi ${ }^{1}$, Takeshi Yamada ${ }^{1}$, Osamu Muraoka ${ }^{2}$ and Reiko Tanaka ${ }^{1, *}$ \\ Received: 29 October 2015; Accepted: 16 November 2015; Published: 24 November 2015 \\ Academic Editor: Isabel C. F. R. Ferreira \\ 1 Laboratory of Medicinal Chemistry, Osaka University of Pharmaceutical Sciences, \\ 4-20-1 Nasahara, Takatsuki, Osaka 569-1094, Japan; teppei-727@ezweb.ne.jp (T.M.); \\ saridon55@yahoo.co.jp (S.I.); mini-mini.naoko@hotmail.co.jp (N.I.); rikiaifuni815@yahoo.co.jp (K.H.); \\ minoura@gly.oups.ac.jp (K.M.); t.kikuchi@gly.oups.ac.jp (T.K.); yamada@gly.oups.ac.jp (T.Y.) \\ 2 Laboratory of Pharmaceutical Organic Chemistry, Faculty of Pharmacy Kinki University, \\ 3-4-1 Kowakae, Higashi-osaka, Osaka 577-8502, Japan; muraoka@phar.kindai.ac.jp \\ * Correspondence: tanakar@gly.oups.ac.jp; Tel./Fax: +81-72-690-1084
}

\begin{abstract}
Two new mexicanolide-type limonoids, carapanolides T-U (1-2), and three new phragmalin-type limonoids, carapanolides $\mathrm{V}-\mathrm{X}(3-5)$, were isolated from the seeds of Carapa guianensis (andiroba). Their structures were determined on the basis of 1D- and 2D-NMR spectroscopy.
\end{abstract}

Keywords: Carapa guianensis; Meliaceae; andiroba; seeds; limonoid; mexicanolide; phragmalin; NO production

\section{Introduction}

Limonoids, a series of structurally-diverse and highly-oxygenated tetranortriterpenes, are mainly found in the Meliaceae family and have been attracting attention from biogenetic and synthetic perspectives [1-3]. Carapa guianensis Aublet (Meliaceae), known locally as andiroba, is a tall tropical tree that is widely distributed in the Amazonas State of Brazil, and its wood is extensively used as commercial timber. The towering tree of andiroba grows up to $40 \mathrm{~m}$ in height. Extracts from its bark, flowers and seeds have been used for centuries by the Amazonian people and exhibit various repellent [4], analgesic [5], anti-bacterial [6], anti-inflammatory [7], wound healing [8], anti-malarial [9], anti-allergic [10] and anti-plasmoidal [11] activities, in addition to acute and subacute toxicities [12]. Our previous study on the components of the seed oil of Carapa guianasis revealed the structures of two new unusual 9,10-seco-mexicanolide-type limonoids, carapanolides A and B [13], two novel carbon skeletal limonoids, guianolides A and B [14], and carapanolides C-I [15], carapanolides J-L [16] and carapanolides M-S [17]. We herein describe the isolation and structural determination of five novel limonoids, carapanolides T-X (1-5). The structures of $\mathbf{1}-\mathbf{5}$ were determined on the basis of NMR spectroscopy, including $1 \mathrm{D}$ and $2 \mathrm{D}\left({ }^{1} \mathrm{H},{ }^{1} \mathrm{H}-\mathrm{COSY}, \mathrm{NOESY}, \mathrm{HSQC}\right.$, HMBC) NMR and HRFABMS.

\section{Results and Discussion}

Carapanolide T (1) (Figure 1) was obtained as a colorless amorphous solid, and its molecular formula was established as $\mathrm{C}_{31} \mathrm{H}_{40} \mathrm{O}_{10}\left([\mathrm{M}+\mathrm{H}]^{+} ; m / z\right.$ 573.2704, calcd. for 573.2697) by HRFABMS, implying 12 on the degrees of unsaturation. IR and UV spectra showed the presence of hydroxylgroups at $v_{\max } 3462 \mathrm{~cm}^{-1}$, ester groups at $v_{\max } 1727 \mathrm{~cm}^{-1}$ and $\alpha \beta$-unsaturated $\delta$-lactone at $\lambda_{\max } 230 \mathrm{~nm}\left(\log \varepsilon\right.$ 3.85). ${ }^{1} \mathrm{H}$ - and ${ }^{13} \mathrm{C}-\mathrm{NMR}$ data indicated that eight out of the 12 units of 
unsaturation came from three carbon-carbon double bonds and three ester carbonyls, including a lactone carbonyl and ketone.

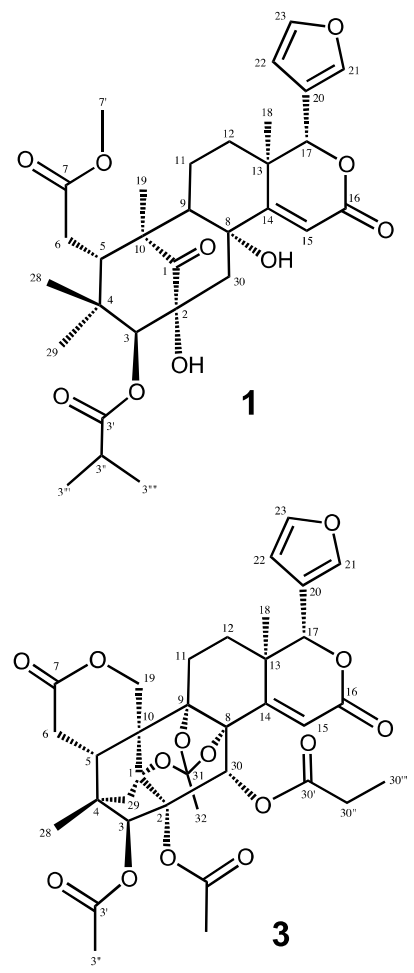

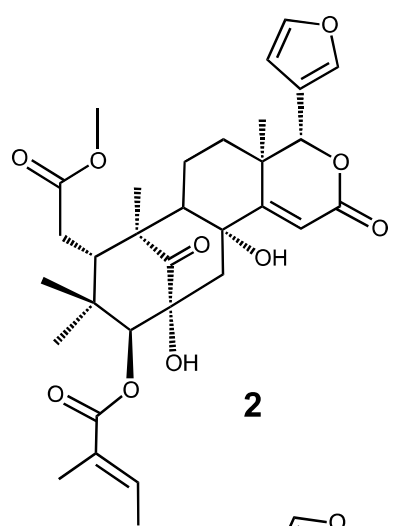

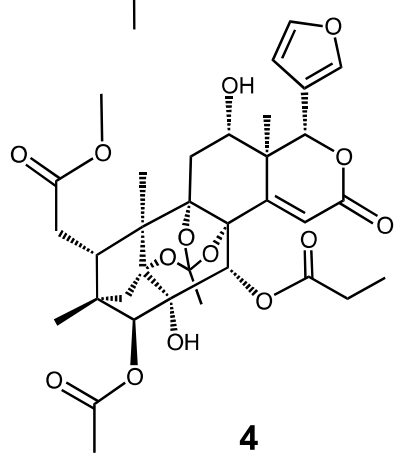

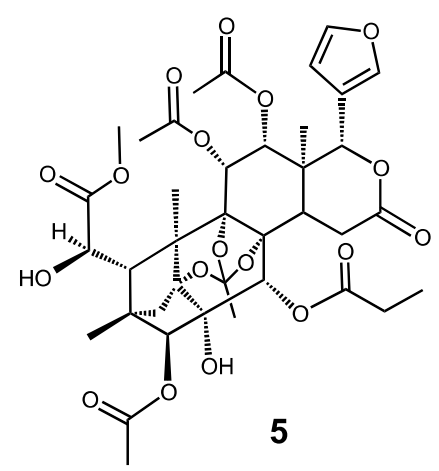

Figure 1. Chemical structures of Compounds 1-5.

Therefore, the remaining degrees of unsaturation required 1 to be pentacyclic. The ${ }^{1} \mathrm{H}$ - and ${ }^{13} \mathrm{C}$-NMR spectra of $\mathbf{1}$ (Table 1 ) indicated the presence of four tertiary methyls $\left(\delta_{\mathrm{H}} 0.69,0.86,1.23,1.27\right.$ (each s)), a 2-methyl propanoyl $\left(\delta_{\mathrm{H}} 1.25\right.$ and 1.27 (each $\left.3 \mathrm{H}, \mathrm{d}\right), 2.71\left(1 \mathrm{H}\right.$, sept); $\delta_{\mathrm{C}} 19.1$ and 19.2 (each q), $34.3(\mathrm{~d}), 176.2(\mathrm{~s}))$, methyl ester $\left(\delta_{\mathrm{H}} 3.71(\mathrm{~s}) ; \delta_{\mathrm{C}} 52.2(\mathrm{q}), 173.6(\mathrm{~s})\right)$, four methylenes $\left(\delta_{\mathrm{C}} 20.7(\mathrm{t}), 32.9(\mathrm{t})\right.$, $33.7(\mathrm{t}), 45.0(\mathrm{t}))$, four $s p^{3}$ methines, including two oxymethines $\left(\delta_{\mathrm{H}} 4.80(\mathrm{~s}), 5.16(\mathrm{~s})\right)$, a furan ring $\left(\delta_{\mathrm{H}} 6.49(\mathrm{dd}), 7.44(\mathrm{t})\right.$, and $\left.7.51(\mathrm{brs})\right)$, an $\alpha, \beta$-unsaturated $\delta$-lactone $\left(\delta_{\mathrm{H}} 5.16(\mathrm{~s}), 6.18(\mathrm{~s}) ; \delta_{\mathrm{C}} 78.8(\mathrm{~d})\right.$, $116.3(\mathrm{~d}), 167.5(\mathrm{~s}))$, five $s p^{3}$ quaternary carbons, including two oxycarbons $\left(\delta_{\mathrm{C}} 72.8(\mathrm{~s}), 76.7(\mathrm{~s})\right)$, and a ketone $\left(\delta_{C} 216.8(\mathrm{~s})\right)$. An analysis of the ${ }^{1} \mathrm{H}^{-1} \mathrm{H}$ COSY spectrum of 1 revealed the partial structures shown in bold face in Figure 2.

In the HMBC spectrum (Figure 2), cross-peaks were observed from Me-18 $\left(\delta_{\mathrm{H}} 1.27(\mathrm{~s})\right)$ to $\mathrm{C}-12$, C-13, C-14 $\left(\delta_{\mathrm{C}} 164.7(\mathrm{~s})\right)$ and C-17 $\left(\delta_{\mathrm{C}} 78.8(\mathrm{~d})\right)$, from Me-19 $\left(\delta_{\mathrm{H}} 1.23(\mathrm{~s})\right)$ to C-1 $\left(\delta_{\mathrm{C}} 216.8(\mathrm{~s})\right), \mathrm{C}-5, \mathrm{C}-9$, and $\mathrm{C}-10$, from $\mathrm{H}-5\left(\delta_{\mathrm{H}} 3.36(\mathrm{dd})\right)$ to $\mathrm{C}-4, \mathrm{C}-6, \mathrm{C}-7\left(\delta_{\mathrm{C}} 173.6(\mathrm{~s})\right)$ and $\mathrm{C}-10$, from $\mathrm{H}_{2}-30\left(\delta_{\mathrm{H}} 2.51\right.$ and 3.55 (each d)) to C-1, C-2 $\left(\delta_{\mathrm{C}} 76.7(\mathrm{~s})\right), \mathrm{C}-3\left(\delta_{\mathrm{C}} 85.5(\mathrm{~d})\right), \mathrm{C}-8\left(\delta_{\mathrm{C}} 72.8(\mathrm{~s})\right)$ and $\mathrm{C}-9$ and from H-15 $\left(\delta_{\mathrm{H}} 6.18(\mathrm{~s})\right)$ to $\mathrm{C}-8, \mathrm{C}-13, \mathrm{C}-14\left(\delta_{\mathrm{C}} 164.7(\mathrm{~s})\right)$ and $\mathrm{C}-17$. In the ${ }^{1} \mathrm{H}-{ }^{1} \mathrm{H}$ COSY spectrum, $\left(\mathrm{H}-5-\mathrm{H}_{2}-6 ; \mathrm{H}-9-\mathrm{H}_{2}-11-\mathrm{H}_{2}-12\right.$; 
$\mathrm{H}-22-\mathrm{H}-23 ; \mathrm{H}-3^{\prime \prime}-\mathrm{H}-3^{\prime \prime \prime}$ and $\left.\mathrm{H}-3^{\prime \prime \prime \prime}\right)$ revealed the partial structure shown in Figure 2. Significant NOE interactions (Figure 2) were observed from $\mathrm{H}-3\left(\delta_{\mathrm{H}} 4.80(\mathrm{~s})\right.$ ) / Me-28, Me-29; $\mathrm{H}-5\left(\delta_{\mathrm{H}} 3.36(\mathrm{dd})\right) / \mathrm{H}-11 \beta$, Me-28, H-30ß; 2-OH ( $\left.\delta_{\mathrm{H}} 4.05(\mathrm{~s})\right) / \mathrm{H}-12 \alpha, \mathrm{Me}-19 ; 8-\mathrm{OH}\left(\delta_{\mathrm{H}} 2.81(\mathrm{~s})\right) / \mathrm{H}-9, \mathrm{H}-12 \alpha, \mathrm{Me}-18 ; \mathrm{H}-17\left(\delta_{\mathrm{H}}\right.$ $5.16(\mathrm{~s})) / \mathrm{H}-5, \mathrm{H}-11 \beta, \mathrm{H}-12 \beta$ and $\mathrm{H}-30 \beta$, which indicated the $\alpha$-orientation of $\mathrm{H}-3, \mathrm{H}-9$, Me-18, Me-19, $2-\mathrm{OH}$ and $8-\mathrm{OH}$ and the $\beta$-orientation of $\mathrm{H}-5$ and $\mathrm{H}-17$. Therefore, the relative structure of 1 was established as shown in Figure 1.
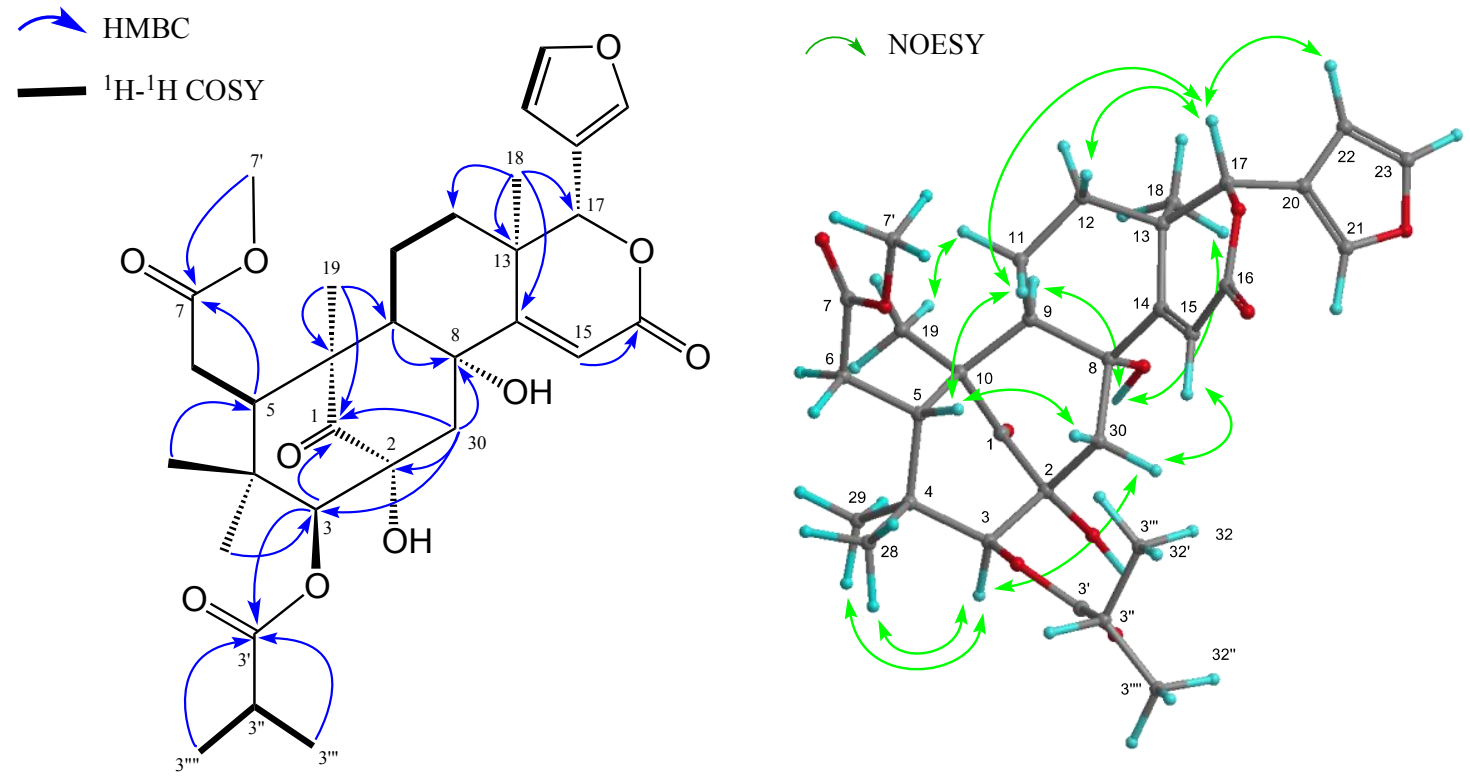

Figure 2. Key HMBC, COSY and NOESY correlations for carapanolide T (1).

Carapanolide $\mathrm{U}(2)$ was isolated as colorless needles and shown to have the molecular formula $\mathrm{C}_{32} \mathrm{H}_{40} \mathrm{O}_{10}\left(\mathrm{~m} / z: 585.2701[\mathrm{M}+\mathrm{H}]^{+}\right.$(calcd for 585.2700) by HRFABMS. IR and UV spectra revealed the presence of hydroxy and ester groups and an $\alpha \beta$-unsaturated $\delta$-lactone at $\nu_{\max } 3537,1748$ and $1719 \mathrm{~cm}^{-1}$, and $\lambda_{\max }$ at $230 \mathrm{~nm}(\log \varepsilon 4.11)$. The ${ }^{1} \mathrm{H}-$ and ${ }^{13} \mathrm{C}-\mathrm{NMR}$ spectra of 2 (Table 1) were very similar to those of $\mathbf{1}$, except for the absence of the 2-methylpropanoyl group at $\mathrm{C}-3$ and the presence of the tigroyl group at C-3. The relative structure of $\mathbf{2}$ was determined as shown in Figure 1.

Carapanolide L (3) was obtained as colorless crystals, and its molecular formula was established as $\mathrm{C}_{35} \mathrm{H}_{38} \mathrm{O}_{14}\left([\mathrm{M}+\mathrm{H}]^{+} ; m / z\right.$ 683.2335, calcd. for 683.2340) by HRFABMS, implying 17 on the index of hydrogen deficiency. IR and UV spectra revealed the presence of ester groups and an $\alpha \beta$-unsaturated $\delta$-lactone at $\gamma_{\max } 1748$ and $1719 \mathrm{~cm}^{-1}$ and $\lambda_{\max }$ at $226 \mathrm{~nm}\left(\log \varepsilon\right.$ 3.73). ${ }^{1} \mathrm{H}$ - and ${ }^{13} \mathrm{C}-\mathrm{NMR}$ data indicated that eight out of the 17 units of unsaturation came from three carbon-carbon double bonds and five ester carbonyls, including two lactone carbonyls. Therefore, the remaining degrees of unsaturation required 3 to be non-acyclic. The ${ }^{1} \mathrm{H}$ - and ${ }^{13} \mathrm{C}-\mathrm{NMR}$ spectra of 3 (Table 2) indicated the presence of two tertiary methyls $\left(\delta_{\mathrm{H}} 1.02,1.14(\right.$ each s) $)$, two acetyls $\left(\delta_{\mathrm{H}} 2.04(\mathrm{~s}), 2.17(\mathrm{~s})\right.$; $\left.\delta_{\mathrm{C}} 20.8(\mathrm{q}), 21.8(\mathrm{q}), 169.1(\mathrm{~s}), 170.1(\mathrm{~s})\right)$, an $n$-propanoyl group $\left(\delta_{\mathrm{H}} 1.07(3 \mathrm{H}, \mathrm{t}), 2.25(1 \mathrm{H}, \mathrm{m}), 2.29\right.$ $\left.(1 \mathrm{H}, \mathrm{m}) ; \delta_{\mathrm{C}} 8.5(\mathrm{q}), 27.4(\mathrm{t}), 173.3(\mathrm{~s})\right)$, an orthoacetyl group $\left(\delta_{\mathrm{H}} 1.68(3 \mathrm{H}, \mathrm{s}) ; \delta_{\mathrm{C}} 20.9(\mathrm{q}), 120.1(\mathrm{~s})\right)$, four methylenes, including an oxymethylene $\left(\delta_{\mathrm{H}} 4.34\right.$ and 4.86 (each $\left.1 \mathrm{H}, \mathrm{d}\right)$, four $s p^{3}$ methines, including three oxymethines $\left(\delta_{\mathrm{H}} 5.10(\mathrm{~s}), 5.27(\mathrm{~s})\right.$ and $\left.5.78(\mathrm{~s})\right)$, a furan ring $\left(\delta_{\mathrm{H}} 6.44(\mathrm{dd}), .44(\mathrm{t})\right.$ and $\left.7.52(\mathrm{brs})\right)$, seven $s p^{3}$ quaternary carbons, including four oxycarbons $\left(\delta_{C} 82.6,83.9,84.2,84.6\right.$ (each s)), and two lactone carbonyl groups $\left(\delta_{\mathrm{C}} 163.0\right.$ and 171.0 (each s)). An analysis of the ${ }^{1} \mathrm{H}-{ }^{1} \mathrm{H}$ COSY spectrum of 3 revealed the partial structures shown in bold face in Figure 3. In the HMBC spectrum (Figure 3), cross-peaks were observed from Me-18 $\left(\delta_{\mathrm{H}} 1.14(\mathrm{~s})\right)$ to $\mathrm{C}-12, \mathrm{C}-13, \mathrm{C}-14\left(\delta_{\mathrm{C}} 159.6\right)$ and $\mathrm{C}-17\left(\delta_{\mathrm{C}}\right.$ 80.4), from Me-28 $\left(\delta_{\mathrm{H}} 1.02(\mathrm{~s})\right)$ to $\mathrm{C}-3\left(\delta_{\mathrm{C}} 81.3\right), \mathrm{C}-4, \mathrm{C}-5$ and C-29, from $\mathrm{H}-30\left(\delta_{\mathrm{H}} 5.78(\mathrm{~s})\right)$ to $\mathrm{C}-1$ $\left(\delta_{\mathrm{C}} 84.6(\mathrm{~s})\right), \mathrm{C}-2\left(\delta_{\mathrm{C}} 84.2(\mathrm{~s})\right), \mathrm{C}-3, \mathrm{C}-8\left(\delta_{\mathrm{C}} 82.6(\mathrm{~s})\right)$ and $\mathrm{C}-9\left(\delta_{\mathrm{C}} 83.9(\mathrm{~s})\right)$ and from H-15 $\left(\delta_{\mathrm{H}} 6.05(\mathrm{~s})\right)$ 
to C-8, C-13, C-14 and C-16 ( $\left.\delta_{\mathrm{C}} 163.0(\mathrm{~s})\right)$. Therefore, the planar structure of 3 was established as phragmalin-1,8,9-orthoacetate [13], and the positions of the two acetyls and an $n$-propyl group were located at C-2, C-3 and C-30, respectively, by detailed ${ }^{1} \mathrm{H}-{ }^{1} \mathrm{H}$ COSY and $\mathrm{HMBC}$ correlations (Figure 3). In the NOESY spectrum, significant NOEs (Figure 3) were observed between H-3 and H-29 pro-S, H-30 and Me-28, between $\mathrm{H}-5 \beta\left(\delta_{\mathrm{H}} 2.72(\mathrm{dd})\right)$ and $\mathrm{H}-12 \beta$, Me-28 and $\mathrm{H}-30$ between $\mathrm{H}-15\left(\delta_{\mathrm{H}} 6.05(\mathrm{~s})\right)$ and $\mathrm{H}-17 \beta$ and $\mathrm{H}-30$, between $\mathrm{H}-17 \beta\left(\delta_{\mathrm{H}} 5.10(\mathrm{~s})\right)$ and $\mathrm{H}-12 \beta, \mathrm{H}-15, \mathrm{H}-22$ and $\mathrm{H}-30 \beta$ and between Me-18 $\left(\delta_{\mathrm{H}} 1.14(\mathrm{~s})\right)$ and $\mathrm{H}-11 \alpha, \mathrm{H}-12 \alpha$ and Me-32. Therefore, the relative structure of 3 was established as shown in Figure 1.

Table $1 .{ }^{1} \mathrm{H}-(600 \mathrm{MHz})$ and ${ }^{13} \mathrm{C}-(150 \mathrm{MHz})$ NMR spectroscopic data of compounds $\mathbf{1}$ and $\mathbf{2}$.

\begin{tabular}{|c|c|c|c|c|c|c|c|}
\hline \multirow{2}{*}{\multicolumn{2}{|c|}{ Position }} & \multicolumn{3}{|c|}{1} & \multicolumn{3}{|c|}{2} \\
\hline & & \multicolumn{2}{|r|}{${ }^{1} \mathrm{H}^{\mathrm{a}}(\mathrm{J}, \mathrm{Hz})$} & \multirow{2}{*}{$\frac{{ }^{13} C^{b}}{216.8}$} & \multicolumn{2}{|c|}{${ }^{1} \mathrm{H}^{\mathrm{a}}(\mathrm{J}, \mathrm{Hz})$} & \multirow{2}{*}{$\frac{{ }^{13} C^{b}}{216.7}$} \\
\hline 1 & & & & & & & \\
\hline 2 & & & & 76.7 & & & 77.0 \\
\hline 3 & & 4.80 & $\mathrm{~s}$ & 85.5 & 4.88 & $\mathrm{~s}$ & 85.8 \\
\hline 4 & & & & 39.7 & & & 40.0 \\
\hline 5 & & 3.36 & $\mathrm{dd}(9.4,1.5)$ & 41.8 & 3.39 & $\mathrm{dd}(7.9,1.1)$ & 41.8 \\
\hline \multirow[t]{2}{*}{6} & $\alpha$ & 2.34 & dd $(17.3,1.5)$ & 32.9 & 2.37 & $\mathrm{~m}$ & 32.9 \\
\hline & $\beta$ & 2.38 & $\mathrm{dd}(17.3,9.4)$ & & 2.34 & $\mathrm{~m}$ & \\
\hline 7 & & & & 173.6 & & & 173.6 \\
\hline 8 & & & & 72.8 & & & 72.9 \\
\hline 9 & & 1.85 & dd $(13.3,6.0)$ & 60.2 & 1.87 & $\mathrm{t}(5.6)$ & 60.1 \\
\hline 10 & & & & 47.9 & & & 47.8 \\
\hline \multirow[t]{2}{*}{11} & $\alpha$ & 1.48 & $\mathrm{~m}$ & 20.7 & 1.67 & $\mathrm{~m}$ & 20.7 \\
\hline & $\beta$ & 1.52 & $\mathrm{~m}$ & & 1.53 & $\mathrm{~m}$ & \\
\hline \multirow[t]{2}{*}{12} & $\alpha$ & 1.28 & $\mathrm{~m}$ & 33.7 & 1.34 & $\mathrm{~m}$ & 33.8 \\
\hline & $\beta$ & 2.00 & ddd $(14.1,6.8,3.6)$ & & & 2.02 & $\mathrm{~m}$ \\
\hline 13 & & & & 38.5 & & & 38.5 \\
\hline 14 & & & & 164.7 & & & 164.6 \\
\hline 15 & & 6.18 & $\mathrm{~s}$ & 116.3 & 6.16 & $\mathrm{~s}$ & 116.3 \\
\hline 16 & & & & 167.5 & & & 167.6 \\
\hline 17 & & 5.16 & $\mathrm{~s}$ & 78.8 & 5.18 & $\mathrm{~s}$ & 79.8 \\
\hline 18 & & 1.27 & $\mathrm{~s}$ & 23.2 & 1.28 & $\mathrm{~s}$ & 23.2 \\
\hline 19 & & 1.23 & $\mathrm{~s}$ & 18.3 & 1.24 & $\mathrm{~s}$ & 18.4 \\
\hline 20 & & & & 119.8 & & & 119.8 \\
\hline 21 & & 7.51 & brs & 141.7 & 7.51 & br s & 141.7 \\
\hline 22 & & 6.49 & $\mathrm{dd}(2.1,0.9)$ & 110.4 & 6.49 & $\mathrm{~m}$ & 110.4 \\
\hline 23 & & 7.44 & $t(2.1)$ & 143.1 & 7.44 & $\mathrm{t}(1.4)$ & 143.1 \\
\hline 28 & & 0.69 & $\mathrm{~s}$ & 22.3 & 0.70 & $\mathrm{~s}$ & 22.4 \\
\hline 29 & & 0.86 & $\mathrm{~s}$ & 22.6 & 0.88 & $\mathrm{~s}$ & 22.6 \\
\hline \multirow[t]{2}{*}{30} & $\alpha$ & 2.51 & $\mathrm{~d}(16.0)$ & 45.0 & 2.52 & $\mathrm{dd}(14.9,1.2)$ & 45.0 \\
\hline & $\beta$ & 3.55 & $\mathrm{~d}(16.0)$ & & 3.58 & $\mathrm{~d}(14.9)$ & \\
\hline $3^{\prime}$ & & & & 176.2 & & & 167.2 \\
\hline $3^{\prime \prime}$ & & 2.71 & sept (6.7) & 34.3 & & & 128.1 \\
\hline $3^{\prime \prime \prime}$ & & 1.25 & $\mathrm{~d}(6.7)$ & 19.1 & 6.96 & $\mathrm{q}(7.1)$ & 138.8 \\
\hline $3^{\prime \prime \prime \prime}$ & & 1.27 & $d(6,7)$ & 19.2 & 1.88 & $\mathrm{~d}(7.1)$ & 14.7 \\
\hline $3^{\prime \prime \prime \prime \prime \prime}$ & & & & & 1.92 & $\mathrm{~s}$ & 12.4 \\
\hline $7^{\prime}$ & & 3.71 & $\mathrm{~s}$ & 52.2 & 3.70 & $\mathrm{~s}$ & 52.1 \\
\hline $2-\mathrm{OH}$ & & 4.05 & $\mathrm{~s}$ & & & & \\
\hline $8-\mathrm{OH}$ & & 2.81 & $\mathrm{~s}$ & & & & \\
\hline
\end{tabular}

${ }^{\text {a }}$ Measured at $600 \mathrm{MHz}$ in $\mathrm{CDCl}_{3} .{ }^{\mathrm{b}}$ Measured at $150 \mathrm{MHz}$ in $\mathrm{CDCl}_{3}$. 

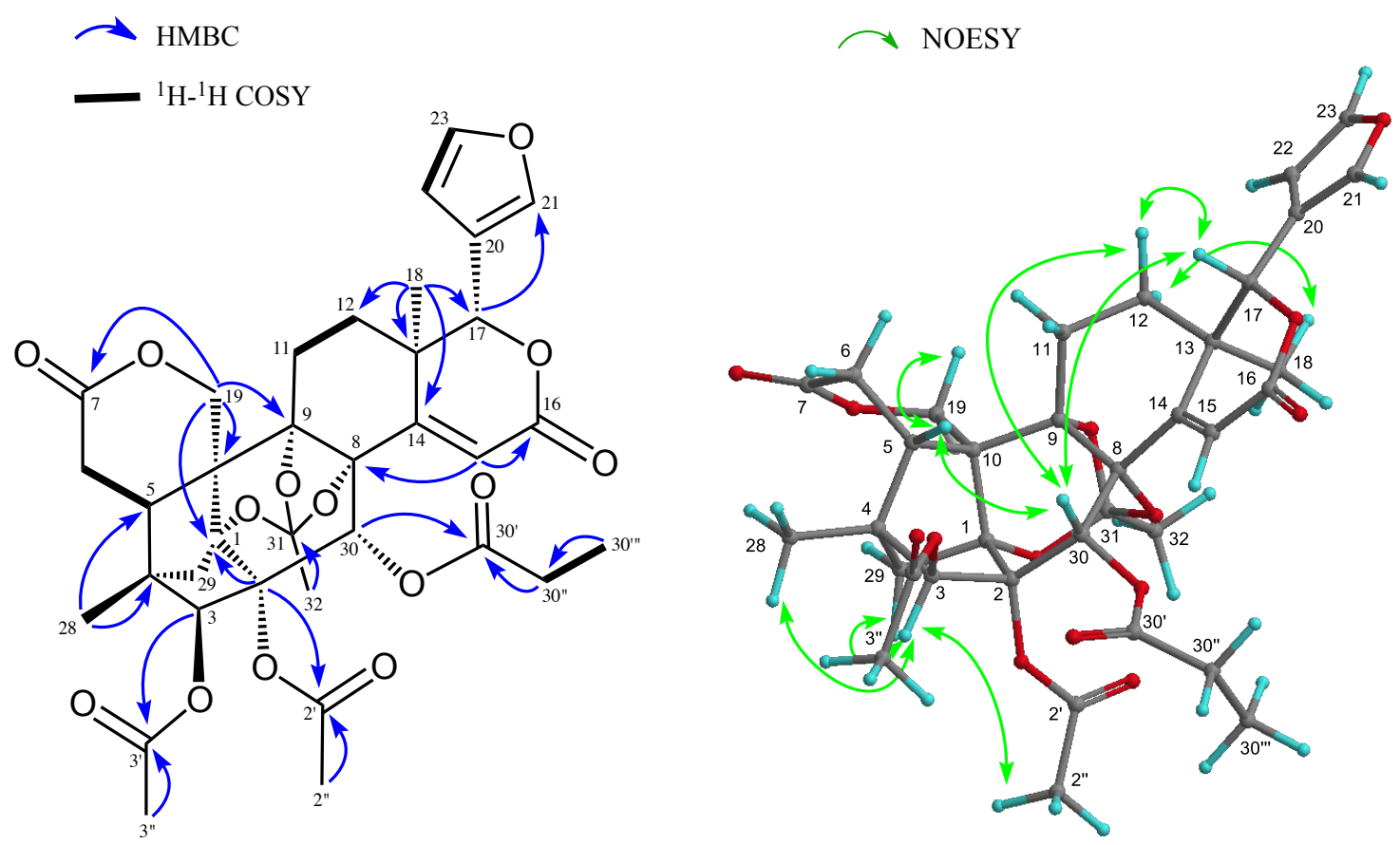

Figure 3. Key HMBC, COSY and NOESY correlations for carapanolide V (3).

Carapanolide W (4) was obtained as colorless crystals, and its molecular formula was established as $\mathrm{C}_{34} \mathrm{H}_{40} \mathrm{O}_{14}\left([\mathrm{M}+\mathrm{H}]^{+} ; m / z\right.$ 673.2492, calcd. for 673.2496) by HRFABMS. IR and UV spectra revealed the presence of hydroxy groups and ester groups and an $\alpha \beta$-unsaturated $\delta$-lactone at $\nu_{\max } 3657,1728$ and $1698 \mathrm{~cm}^{-1}$ and $\lambda_{\max }$ at $230 \mathrm{~nm}\left(\log \varepsilon\right.$ 3.73). The ${ }^{1} \mathrm{H}$ - and ${ }^{13} \mathrm{C}-\mathrm{NMR}$ spectra of 4 (Table 2$)$ indicated the presence of three tertiary methyl groups $\left(\delta_{\mathrm{H}} 0.74,1.32,1.48\right.$ (each s)), an acetyl $\left(\delta_{\mathrm{H}} 2.09(\mathrm{~s}) ; \delta_{\mathrm{C}}\right.$ $21.7(\mathrm{q}), 169.1(\mathrm{~s}))$, an $n$-propanoyl group $\left(\delta_{\mathrm{H}} 1.16(3 \mathrm{H}, \mathrm{t}), 2.45(2 \mathrm{H}, \mathrm{m}) ; \delta_{\mathrm{C}} 8.9(\mathrm{q}), 28.1(\mathrm{t}), 173.8(\mathrm{~s})\right)$, methyl ester $\left(\delta_{\mathrm{H}} 3.71(3 \mathrm{H}, \mathrm{s}) ; \delta_{\mathrm{C}} 52.3(\mathrm{q}), 173.9(\mathrm{~s})\right)$, three methylene groups, five $s p^{3}$ methine groups, including four oxymethine groups $\left(\delta_{\mathrm{H}} 3.86(\mathrm{dd}), 5.22(\mathrm{~s}), 5.35(\mathrm{~s}), 5.90(\mathrm{~s})\right)$, a furan ring $\left(\delta_{\mathrm{H}} 6.61(\mathrm{dd})\right.$, 7.53 (br s), $7.64(\mathrm{t}))$, seven $s p^{3}$ quaternary carbons, including four oxycarbons $\left(\delta_{\mathrm{C}} 83.5(\mathrm{~s}), 83.7\right.$ (s), 84.2 $(\mathrm{s}), 86.1(\mathrm{~s}))$, three ester carbonyls $\left(\delta_{\mathrm{C}} 169.1(\mathrm{~s}), 173.8(\mathrm{~s}), 173.9(\mathrm{~s})\right)$ and an $\alpha \beta$-unsaturated $\delta$ lactone $\left(\delta_{\mathrm{H}} 6.62(\mathrm{~s}), \delta_{\mathrm{C}} 123.7(\mathrm{~d}), 163.5(\mathrm{~s})\right)$. Cross-peaks were observed in the HMBC spectrum, from Me-18 $\left(\delta_{\mathrm{H}} 1.48(\mathrm{~s})\right)$ to $\mathrm{C}-12\left(\delta_{\mathrm{C}} 66.6(\mathrm{~d})\right), \mathrm{C}-13, \mathrm{C}-14\left(\delta_{\mathrm{C}} 153.8(\mathrm{~s})\right)$ and C-17 $\left(\delta_{\mathrm{C}} 78.8(\mathrm{~d})\right)$, from Me-19 $\left(\delta_{\mathrm{H}}\right.$ $1.32(\mathrm{~s}))$ to $\mathrm{C}-1\left(\delta_{\mathrm{C}} 84.2(\mathrm{~s})\right), \mathrm{C}-5, \mathrm{C}-9\left(\delta_{\mathrm{C}} 86.1(\mathrm{~s})\right)$ and C-10, from H-15 $\left(\delta_{\mathrm{H}} 6.62(\mathrm{~s})\right)$ to C-8 $\left(\delta_{\mathrm{C}} 83.7(\mathrm{~s})\right)$, C-13, C-14 and C-16 ( $\left.\delta_{\mathrm{C}} 163.5(\mathrm{~s})\right)$ and from H-30 ( $\left.\delta_{\mathrm{H}} 5.35(\mathrm{~s})\right)$ to C-1 $\left(\delta_{\mathrm{C}} 84.2(\mathrm{~s})\right), \mathrm{C}-2\left(\delta_{\mathrm{C}} 83.5(\mathrm{~s})\right)$, C-3 $\left(\delta_{\mathrm{C}} 85.0(\mathrm{~d})\right), \mathrm{C}-8$ and C-9. The singlet oxymethine proton at $\delta_{\mathrm{H}} 5.22$ was assigned to C-3 through HMBC correlations to C-1, C-2, C-5, C-28, C-29, C-30 $\left(\delta_{C} 74.3(d)\right)$ and C-3' $\left(\delta_{C} 169.1(\mathrm{~s})\right)$, while another singlet proton at $\delta_{\mathrm{H}} 5.35$, showing HMBC correlations to C-1, C-2, C-8, C-9, C-14 ( $\left.\delta_{\mathrm{C}} 153.8(\mathrm{~s})\right)$ and $\mathrm{C}-30^{\prime}\left(\delta_{\mathrm{C}} 173.8(\mathrm{~s})\right)$, was assigned to C-30. An oxymethine proton at $\delta_{\mathrm{H}} 5.22(\mathrm{dd})$ was assigned to C-12 through HMBC correlations to C-9, C-11, C-13, C-14, C-17 $\left(\delta_{\mathrm{C}} 78.8(\mathrm{~d})\right)$ and C-18. In an analysis of the ${ }^{1} \mathrm{H}-{ }^{1} \mathrm{H}$ COSY spectrum of $\left.4, \mathrm{H}-5-\mathrm{H}_{2}-6 ; \mathrm{H}_{2}-11-\mathrm{H}-12 ; \mathrm{H}-22-\mathrm{H}-23 ; \mathrm{H}-30^{\prime \prime}-\mathrm{H}-30^{\prime \prime \prime}\right)$ revealed the partial structure. The relative configuration of 4 was established on the basis of NOE interactions. Significant NOE interactions were observed from H-5 $\left(\delta_{\mathrm{H}} 2.11(\mathrm{~m})\right) / \mathrm{H}-11 \beta, \mathrm{H}-30, \mathrm{Me}-28 ; \mathrm{H}-30\left(\delta_{\mathrm{H}} 5.35(\mathrm{~s})\right) / \mathrm{H}-3$, $\mathrm{H}-5, \mathrm{H}-15 ; \mathrm{H}-17\left(\delta_{\mathrm{H}} 5.90(\mathrm{~s})\right) / \mathrm{H}-5, \mathrm{H}-12 \beta, \mathrm{H}-15, \mathrm{H}-21, \mathrm{H}-22$, which indicated the $\alpha$-orientation of H-3, Me-18 and Me-19 and the $\beta$-orientation of $\mathrm{H}-5, \mathrm{H}-12, \mathrm{H}-17$ and $\mathrm{H}-30$. Therefore, the relative structure of 4 was established as shown in Figure 1. 
Table 2. ${ }^{1} \mathrm{H}-(600 \mathrm{MHz})$ and ${ }^{13} \mathrm{C}-(150 \mathrm{MHz})$ NMR spectroscopic data of compounds 3-5.

\begin{tabular}{|c|c|c|c|c|c|c|c|c|c|c|}
\hline \multirow{2}{*}{\multicolumn{2}{|c|}{ Position }} & \multirow{2}{*}{\multicolumn{2}{|c|}{$\begin{array}{r}3 \\
{ }^{1} \mathrm{H}^{\mathrm{a}}(J,\end{array}$}} & \multicolumn{4}{|c|}{4} & \multicolumn{3}{|c|}{5} \\
\hline & & & & \multirow{2}{*}{$\frac{{ }^{13} \mathbf{C}^{\mathbf{b}}}{84.6}$} & \multicolumn{2}{|c|}{${ }^{1} \mathrm{H}^{\mathrm{a}}(J, \mathrm{~Hz})$} & \multirow{3}{*}{$\frac{{ }^{13} \mathrm{C}^{\mathrm{b}}}{84.2}$} & \multicolumn{2}{|c|}{${ }^{1} \mathrm{H}^{\mathrm{a}}(J, \mathrm{~Hz})^{\mathrm{a}}$} & \multirow{2}{*}{$\frac{\delta_{C}{ }^{\mathbf{b}}}{85.1}$} \\
\hline & & & & & & & & & & \\
\hline 2 & & & & 84.2 & & & & & & 79.6 \\
\hline 3 & & 5.27 & $\mathrm{~s}$ & 81.3 & 5.22 & $\mathrm{~s}$ & 85.0 & 4.59 & $\mathrm{~s}$ & 83.7 \\
\hline 4 & & & & 46.4 & & & 44.6 & & & 45.5 \\
\hline 5 & & 2.72 & $\mathrm{dd}(4.7,3.2)$ & 33.8 & 2.11 & $\mathrm{~m}$ & 39.9 & 3.30 & brs & 40.1 \\
\hline \multirow[t]{2}{*}{6} & $\alpha$ & 2.64 & $\mathrm{dd}(17.0,3.2)$ & 68.6 & 2.34 & $\mathrm{~m}$ & 33.7 & 5.98 & brs & 71.5 \\
\hline & $\beta$ & 2.59 & $\mathrm{dd}(17.0,4.7)$ & & 2.36 & $\mathrm{~m}$ & & & & \\
\hline 7 & & & & 171.0 & & & 173.9 & & & 169.4 \\
\hline 8 & & & & 82.6 & & & 83.7 & & & 84.8 \\
\hline 9 & & & & 83.9 & & & 86.1 & & & 86.0 \\
\hline 10 & & & & 46.9 & & & 48.1 & & & 46.2 \\
\hline \multirow[t]{2}{*}{11} & $\alpha$ & 2.19 & $\mathrm{~m}$ & 25.6 & 1.97 & $\mathrm{~m}$ & 34.6 & 4.49 & $\mathrm{~d}(2.3)$ & 69.4 \\
\hline & $\beta$ & 2.33 & $\mathrm{~m}$ & & 2.21 & dd $(14.7,4.1)$ & & & & \\
\hline \multirow[t]{2}{*}{12} & $\alpha$ & 1.50 & $\mathrm{~m}$ & 26.5 & 3.86 & $\mathrm{dd}(13.5,4.1)$ & 66.6 & 4.48 & $\mathrm{~d}(2.3)$ & 71.7 \\
\hline & $\beta$ & 1.64 & $\mathrm{~m}$ & & & & & & & \\
\hline 13 & & & & 37.6 & & & 44.8 & & & 38.4 \\
\hline 14 & & & & 159.6 & & & 153.8 & 2.79 & $\mathrm{dd}(10.4,0.6)$ & 42.3 \\
\hline \multirow[t]{2}{*}{15} & & 6.05 & $\mathrm{~s}$ & 121.0 & 6.62 & $\mathrm{~s}$ & 123.7 & 2.90 & $\mathrm{dd}(18.7,10.4)$ & 26.9 \\
\hline & & & & & & & & 3.22 & $\mathrm{dd}(18.7,0.6)$ & \\
\hline 16 & & & & 163.0 & & & 163.5 & & & 170.8 \\
\hline 17 & & 5.10 & $\mathrm{~s}$ & 80.4 & 5.90 & $\mathrm{~s}$ & 78.8 & 5.98 & $\mathrm{~s}$ & 76.9 \\
\hline 18 & & 1.14 & $\mathrm{~s}$ & 18.7 & 1.48 & $\mathrm{~s}$ & 13.0 & 1.43 & $\mathrm{~s}$ & 15.8 \\
\hline \multirow[t]{2}{*}{19} & $\alpha$ & 4.86 & $\mathrm{~d}(14.0)$ & 31.4 & 1.32 & $\mathrm{~s}$ & 15.5 & 1.23 & $\mathrm{~s}$ & 13.8 \\
\hline & $\beta$ & 4.34 & $\mathrm{~d}(14.0)$ & & & & & & & \\
\hline 20 & & & & 119.4 & & & 121.4 & & & 120.9 \\
\hline 21 & & 7.52 & brs & 141.4 & 7.53 & br s & 144.8 & 7.48 & brs & 141.0 \\
\hline 22 & & 6.44 & $\mathrm{dd}(1.7,0.6)$ & 109.7 & 6.61 & $\mathrm{dd}(1.7,0.9)$ & 109.6 & 6.46 & $\mathrm{dd}(1.8,1.5)$ & 110.9 \\
\hline 23 & & 7.44 & $\mathrm{t}(1.7)$ & 143.3 & 7.64 & $\mathrm{t}(1.7)$ & 142.4 & 7.00 & $t(1.8)$ & 143.1 \\
\hline 28 & & 1.02 & $\mathrm{~s}$ & 14.2 & 0.74 & $\mathrm{~s}$ & 14.5 & 1.10 & $\mathrm{~s}$ & 15.4 \\
\hline \multirow[t]{2}{*}{29} & pro- $R$ & 1.78 & $\mathrm{~d}(11.6)$ & 39.2 & 1.72 & $\mathrm{~d}(11.5)$ & 39.8 & 1.81 & $\mathrm{~d}(10.9))$ & 39.9 \\
\hline & pro-S & 2.38 & $\mathrm{~d}(11.6)$ & & 1.96 & $\mathrm{~d}(11.5)$ & & 2.06 & $\mathrm{~d}(10.9)$ & \\
\hline 30 & & 5.78 & $\mathrm{~s}$ & 68.1 & 5.35 & $\mathrm{~s}$ & 74.3 & 6.01 & $\mathrm{~s}$ & 69.8 \\
\hline 31 & & & & 120.1 & & & 119.7 & & & 119.3 \\
\hline 32 & & 1.68 & $\mathrm{~s}$ & 20.9 & 1.70 & $\mathrm{~s}$ & 16.5 & 1.76 & $\mathrm{~s}$ & 21.1 \\
\hline $2^{\prime}$ & & & & 170.1 & & & & & & \\
\hline $2^{\prime \prime}$ & & 2.17 & $\mathrm{~s}$ & 21.8 & & & & & & \\
\hline $3^{\prime}$ & & & & 169.1 & & & 169.1 & & & 169.6 \\
\hline $3^{\prime \prime}$ & & 2.04 & $\mathrm{~s}$ & 20.8 & 2.09 & $\mathrm{~s}$ & 21.7 & 2.18 & $\mathrm{~s}$ & 21.2 \\
\hline $7^{\prime}$ & & & & & 3.71 & $\mathrm{~s}$ & 52.3 & 3.69 & $\mathrm{~s}$ & 53.1 \\
\hline $11^{\prime}$ & & & & & & & & & & 169.7 \\
\hline $11^{\prime \prime}$ & & & & & & & & 2.22 & $\mathrm{~s}$ & 21.4 \\
\hline $12^{\prime}$ & & & & & & & & & & 169.6 \\
\hline $12^{\prime \prime}$ & & & & & & & & 1.70 & $\mathrm{~s}$ & 20.1 \\
\hline $30^{\prime}$ & & & & 173.3 & & & 173.8 & & & 172.5 \\
\hline \multirow[t]{2}{*}{$30^{\prime \prime}$} & A & 2.25 & $\mathrm{~m}$ & 27.4 & 2.45 & $\mathrm{~m}$ & 28.1 & 2.38 & $\mathrm{dq}(11.2,7.3)$ & 27.9 \\
\hline & B & 2.29 & $\mathrm{~m}$ & & & & & 2.38 & $\mathrm{dq}(11.2,7.3)$ & \\
\hline $30^{\prime \prime \prime}$ & & 1.07 & $\mathrm{t}(7.6)$ & 8.5 & 1.16 & $\mathrm{t}(7.7)$ & 8.9 & 1.09 & $t(7.3)$ & 8.6 \\
\hline
\end{tabular}

Carapanolide X (5) was isolated as a colorless amorphous solid and had the molecular formula $\mathrm{C}_{38} \mathrm{H}_{46} \mathrm{O}_{18}\left([\mathrm{M}+\mathrm{H}]^{+} ; m / z\right.$ 791.2765, calcd. for 791.2763) as determined by HRFABMS. The IR spectrum showed the presence of a hydroxyl at $v_{\max } 3352 \mathrm{~cm}^{-1}$ and ester groups at $v_{\max } 1742 \mathrm{~cm}^{-1}$. ${ }^{1} \mathrm{H}$ - and ${ }^{13} \mathrm{C}$-NMR spectra (Table 2$)$ indicated the presence of three methyls $\left(\delta_{\mathrm{H}} 1.10,1.23,1.43\right.$ (each $3 \mathrm{H}, \mathrm{s}))$, three acetyl groups $\left(\delta_{\mathrm{H}} 1.70,2.18,2.22\right.$ (each $\left.\left.3 \mathrm{H}, \mathrm{s}\right)\right)$, a propanoyl group $\left(\delta_{\mathrm{H}} 1.09(3 \mathrm{H}, \mathrm{t})\right.$, $\left.2.38(2 \mathrm{H}, \mathrm{dq}), \delta_{\mathrm{C}} 172.5(\mathrm{~s})\right)$, a methoxycarbonyl group $\left(\left(\delta_{\mathrm{H}} 3.69(3 \mathrm{H}, \mathrm{s}), \delta_{\mathrm{C}} 53.1(\mathrm{q}), 169.4(\mathrm{~s})\right), s p^{3}\right.$ methylene $\left(\left(\delta_{\mathrm{C}} 26.9(\mathrm{t})\right), \delta\right.$-lactone $\left(\delta_{\mathrm{H}} 5.98(1 \mathrm{H}, \mathrm{s}), \delta_{\mathrm{C}} 76.9(\mathrm{~d}), 170.8(\mathrm{~s})\right)$, a tertiary hydroxyl group $\left(\delta_{\mathrm{C}} 79.6(\mathrm{~s})\right)$, seven $s p^{3}$ methines, including five oxymethines $\left(\delta_{\mathrm{H}} 4.48(\mathrm{~d}), 4.49(\mathrm{~d}), 4.59(\mathrm{~s}), 5.98(\mathrm{~s})\right)$, seven $s p^{3}$ quaternary carbons, including four oxycarbons $\left(\delta_{C} 79.6(\mathrm{~s}), 84.8(\mathrm{~s}), 85.1(\mathrm{~s}), 86.0(\mathrm{~s})\right)$, and a furan ring $\left(\delta_{\mathrm{H}} 6.46(\mathrm{dd}), 7.00(\mathrm{t}), 7.48(\mathrm{brs})\right)$. In the HMBC spectrum, cross-peaks were observed between Me-18 $\left(\delta_{\mathrm{H}} 1.43(\mathrm{~s})\right)$ and C-12 $\left(\delta_{\mathrm{C}} 71.7(\mathrm{~d})\right), \mathrm{C}-13, \mathrm{C}-14$ and C-17 $\left(\delta_{\mathrm{C}} 76.9(\mathrm{~d})\right)$, between Me-19 
$\left(\delta_{\mathrm{H}} 1.23(\mathrm{~s})\right)$ and $\mathrm{C}-1\left(\delta_{\mathrm{C}} 85.1(\mathrm{~s})\right), \mathrm{C}-5, \mathrm{C}-9\left(\delta_{\mathrm{C}} 86.0(\mathrm{~s})\right)$ and C-10, between Me-28 $\left(\delta_{\mathrm{H}} 1.10(\mathrm{~s})\right)$ and C-3 $\left(\delta_{\mathrm{C}} 83.7(\mathrm{~d})\right), \mathrm{C}-4, \mathrm{C}-5$ and C-29 and between H-3 $\left(\delta_{\mathrm{H}} 4.59(\mathrm{~s})\right)$ and C-1 and C-2 $\left(\delta_{\mathrm{C}} 79.6(\mathrm{~s})\right), \mathrm{C}-4$, C-5, C-28, C-29, C-30 $\left(\delta_{\mathrm{C}} 69.8(\mathrm{~d})\right)$ and C-3' $\left(\delta_{\mathrm{C}} 169.6(\mathrm{~s})\right)$, between H-5 $\left(\delta_{\mathrm{H}} 3.30(\mathrm{brs})\right)$ and C-1, C-3, C-4, C-6 $\left(\delta_{C} 71.5(d)\right), C-7\left(\delta_{C} 169.4(s)\right), C-10, C-19, C-28$ and C-29, between H-6 $\left(\delta_{\mathrm{H}} 5.98(\mathrm{brs})\right)$ and C-4, C-5, C-7 and C-10 and between H-30 $\left(\delta_{\mathrm{H}} 6.01(\mathrm{~s})\right)$ and C-1, C-2, C-3, C-8 $\left(\delta_{\mathrm{C}} 84.8(\mathrm{~s})\right), \mathrm{C}-9$ and $\mathrm{C}-30^{\prime}\left(\delta_{\mathrm{C}} 172.5(\mathrm{~s})\right)$. In the ${ }^{1} \mathrm{H}-{ }^{1} \mathrm{H}$ COSY spectrum, (H-5-H-6; H-11-H-12; H-14- $\mathrm{H}_{2}-15 ; \mathrm{H}-22-\mathrm{H}-23$ and $\left.\mathrm{H}-30^{\prime \prime}-\mathrm{H}-30^{\prime \prime \prime}\right)$ was observed. Therefore, the positions of two hydroxyls, a propanoyl and a methoxycarbonyl were located at C-2, C-6, C-30 and C-7, while three acetyl groups were located at C-3, C-11 and C-12, respectively (Figure 4). In the NOESY experiments, cross peaks (Figure 4) were observed between $\mathrm{H}-3\left(\delta_{\mathrm{H}} 4.59(\mathrm{~s})\right)$ and $\mathrm{H}-29$ pro-S, $\mathrm{H}-30$ and Me-28, between $\mathrm{H}-5\left(\delta_{\mathrm{H}} 3.30(\mathrm{brs})\right)$ and Me-28 and H-30, between H-6 ( $\delta_{\mathrm{H}} 5.98$ (brs)) and $\mathrm{H}-5 \beta$ and $\mathrm{H}-11$, between $\mathrm{H}-11\left(\delta_{\mathrm{H}} 4.49(\mathrm{~d})\right)$ and $\mathrm{H}-5 \beta$ and $\mathrm{H}-12$, between $\mathrm{H}-12\left(\delta_{\mathrm{H}} 4.48(\mathrm{~d})\right)$ and $\mathrm{H}-5 \beta, \mathrm{H}-11$ and $\mathrm{H}-17 \beta$, between $\mathrm{H}-30 \beta\left(\delta_{\mathrm{H}} 6.01(\mathrm{~s})\right)$ and $\mathrm{H}-11$ and $\mathrm{H}-12$ and between Me-19 and $\mathrm{H}-6$ and Me-32. Therefore, the propanoyl group at C-30 and acetoxy groups at C-11 and C-12 were all $\alpha$, while the acetoxy group at C-3 had a $\beta$ orientation. The configuration of C-6 was presumed to be $R$, which was the same as that of carapanolide N [17].
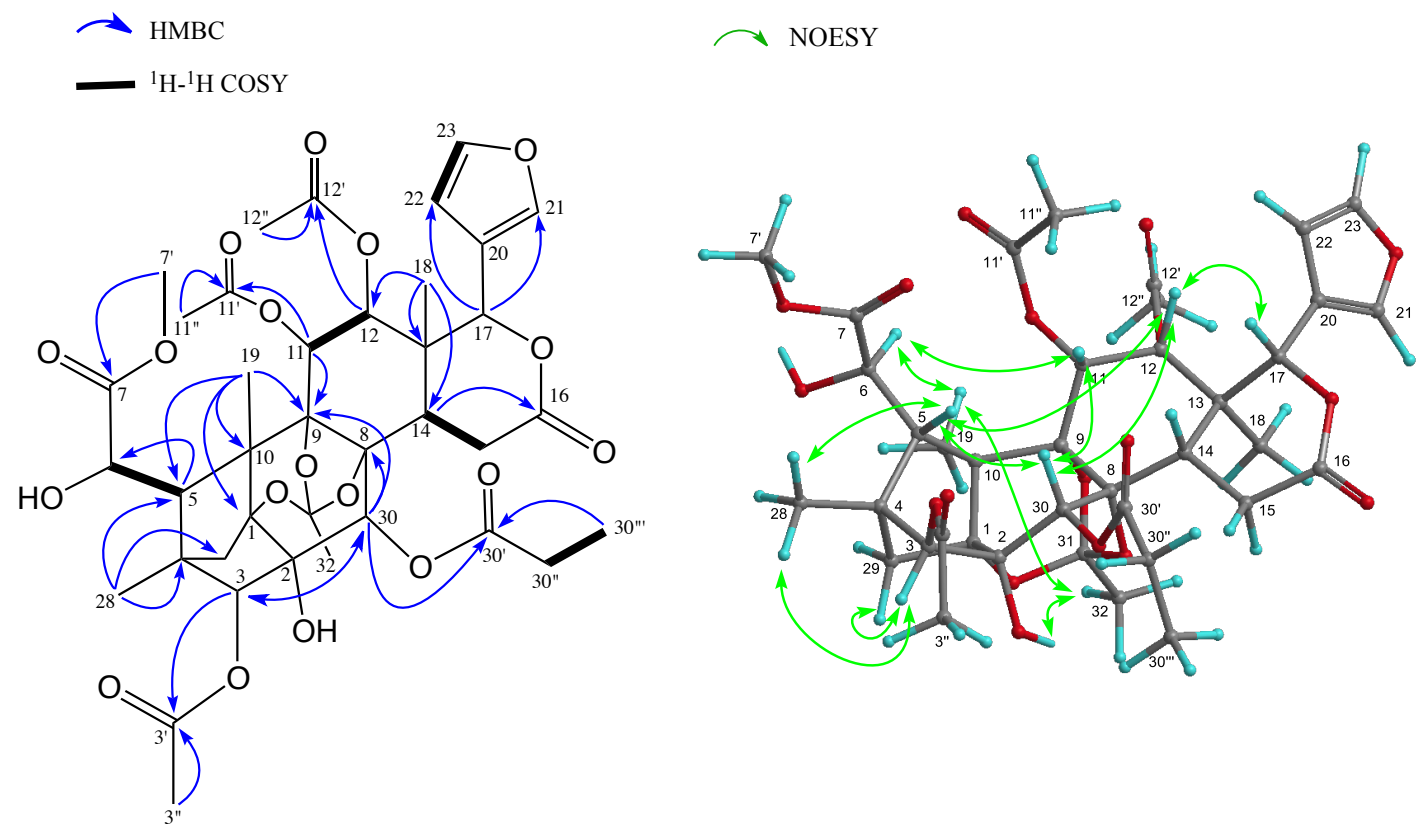

Figure 4. Key HMBC, COSY and NOESY correlations for carapanolide X (5).

Macrophages may be a potential therapeutic target for inflammatory diseases [18]. Activated macrophages release pro-inflammatory mediators, such as NO, reactive oxygen, interleukin- 1 beta, tumor necrosis factor-alpha and other inflammatory mediators, which play important roles in biological defense. However, the overexpression of these mediators had been implicated in diseases, such as osteoarthritis, rheumatoid arthritis and diabetes, because the increased production of pro-inflammatory mediators has been shown to induce severe or chronic inflammation [18]. In the present study, four limonoids and $N^{\mathrm{G}}$-monomethyl-L-arginine acetate (L-NMMA), an inducible nitric oxide synthase (iNOS) inhibitor, were evaluated for their inhibitory effects on NO production in LPS-stimulated RAW264.7 cells (Figure 5). To determine safe concentrations, the cytotoxicities of these limonoids against RAW 264.7 were assessed by the MTT assay. In the NO inhibitory assay, Compounds 1 and 2 exhibited comparable NO inhibitory activities $\left(\mathrm{IC}_{50}\right.$ 1: $22.0 \mu \mathrm{M}$; 2: $23.3 \mu \mathrm{M}$ ) to L-NMMA ( $\mathrm{IC}_{50} 23.9 \mu \mathrm{M}$ ). Of these, 2 did not show cytotoxicities at 1-30 $\mu \mathrm{M}$. Compound 1 exhibited low cytotoxicity at $30 \mu \mathrm{M}$, but not at the effective concentration, namely $10 \mu \mathrm{M}$. Compounds 3-5 did not exhibit inhibitory effects on macrophage activation $\left(\mathrm{IC}_{50}>30 \mu \mathrm{M}\right)$. These 
results suggested that Compounds $\mathbf{1}$ and $\mathbf{2}$ have potential as anti-inflammatory disease agents. In a previous study, we revealed inhibitory activities on NO production of a phragmalin-type limonoid, such as carapanolide $\mathrm{J}\left(\mathrm{IC}_{50} 37.4 \mu \mathrm{M}\right)$ [16], and gedunin-type limonoids, such as 7-deacetoxy-7-oxogedunin ( $\mathrm{IC}_{50} 12.8 \mu \mathrm{M}$ ), 6 $\alpha$-acetoxygedunin ( $\mathrm{IC}_{50} 7.9 \mu \mathrm{M}$ ), $6 \alpha$-hydroxygedunin $\left(\mathrm{IC}_{50} 19.1 \mu \mathrm{M}\right), 6 \alpha$-acetoxy-7 $\alpha$-deacetoxy-7 $\alpha$-hydroxygedunin $\left(\mathrm{IC}_{50} 9.4 \mu \mathrm{M}\right)$, gedunin $\left(\mathrm{IC}_{50} 4.6 \mu \mathrm{M}\right)$ and 7-deacetoxy-7-hydroxygedunin ( $\mathrm{IC}_{50} 8.4 \mu \mathrm{M}$ ), [19]. Compounds 1 and 2 exhibited stronger inhibitory activities on NO production than carapanolide J, however weaker than the gedunin-type limonoids. These data suggest that gedunin-type limonoids are more effective for the inhibition of NO production than phragmalin-type ones in general.
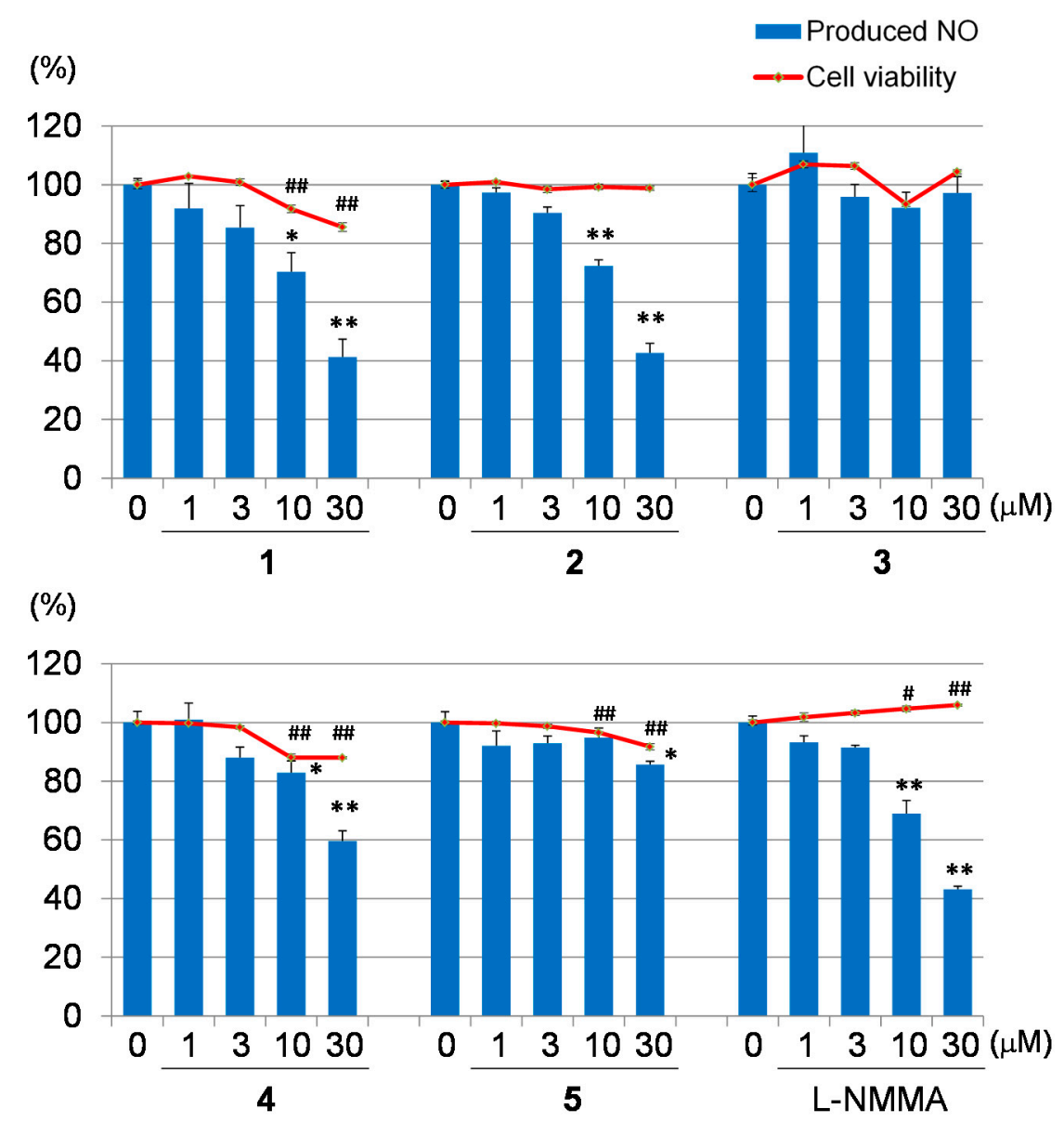

Figure 5. Inhibitory activities on NO production and cytotoxicities of Compounds 1-5 and L-NMMA. Each value represents the mean \pm the standard error (S.E.) of four determinations. Significant differences from the vehicle control $(0 \mu \mathrm{M})$ group shown as ${ }^{*} p<0.05$ and ${ }^{* *} p<0.01$ in the NO inhibitory assay and \# $p<0.05$ and \#\# $p<0.01$ in the cytotoxicity assay.

\section{Experimental Section}

\subsection{General Procedures}

Melting points were determined on a Yanagimoto micro-melting point apparatus and were uncorrected. Optical rotations were measured using a JASCO DIP-1000 digital polarimeter. IR spectra were recorded using a Perkin-Elmer 1720X FTIR spectrophotometer (Perkin-Elmer Inc., Wellesley, MA, USA). ${ }^{1} \mathrm{H}$ - and ${ }^{13} \mathrm{C}-\mathrm{NMR}$ spectra were obtained on an Agilent vnmrs 600 spectrometer (Agilent Technologies, Santa Clara, CA, USA) with standard pulse sequences, operating at 600 and 150 $\mathrm{MHz}$, respectively. $\mathrm{CDCl}_{3}$ was used as the solvent and TMS as the internal standard. FABMS 
were recorded on a JEOL-7000 mass spectrometer (JEOL, Tokyo, Japan). Column chromatography was performed over silica gel (70-230 mesh, Merck, Darmstadt, Germany), while medium pressure liquid chromatography (MPLC) was conducted with silica gel (230-400 mesh, Merck). HPLC was run on a JASCO PU-1586 instrument (JASCO, Tokyo, Japan) equipped with a differential refractometer (RI 1531). Fractions obtained from column chromatography were monitored by TLC (silica gel $60 \mathrm{~F}_{254}$, Merck).

\subsection{Plant Material}

The oil of (2.03 kg) Carapa guianensis AUBLET (Meliaceae) was collected in the Amazon, Brazil, in March 2013, and was kindly provided by Mr. Akira Yoshino (who is a representative of the "NGO Green Heart Love Amazon Project"). A voucher specimen (CGS-01-2) was deposited in the Herbarium of the Laboratory of Medicinal Chemistry, Osaka University of Pharmaceutical Sciences.

\subsection{Isolation of Compounds $\mathbf{1}-\mathbf{5}$}

The seed oil of Carapa guianensis AUBLET (Meliaceae) $\left(2.03 \mathrm{~kg}\right.$ ) was dissolved in $\mathrm{CHCl}_{3}$, and the $\mathrm{CHCl}_{3}$ solution was subjected to CC (silica gel $14 \mathrm{~kg}$ ), affording 7 fractions: Fraction A (fraction (Fr.) No. 1-85, $1.512 \mathrm{~kg}$ ) was eluted with $n$-hexane- $\mathrm{CHCl}_{3}=1: 1$; B (Fr. No. 86-179, $229.1 \mathrm{~g}$ ) was eluted with $\mathrm{CHCl}_{3} ; \mathrm{C}$ (Fr. No. 180-20, $29.3 \mathrm{~g}$ ) was eluted with $\mathrm{CHCl}_{3}-\mathrm{EtOAc}=5: 1$; D (Fr. No. 221-225, $13.2 \mathrm{~g}$ ) was eluted with $\mathrm{CHCl}_{3}-\mathrm{EtOAc}=2: 1$; E (Fr. No. 226-265, $84.5 \mathrm{~g}$ ) was eluted with $\mathrm{CHCl}_{3}$-EtOAc = 2:1; F (Fr. No. 266-290, $25.3 \mathrm{~g}$ ) was eluted with EtOAc; G (Fr. No. 291-315, $72.8 \mathrm{~g}$ ) was eluted with EtOAc: $\mathrm{MeOH}=5: 1$; and H (Fr. No. 316-333, $45.4 \mathrm{~g}$ ) was eluted with MeOH. Residue D was rechromatographed over a silica gel column (CC) (230-400 mesh, 300 g) eluted with n-hexane-EtOAc (1:1) to give 13 fractions: D1 (Fr. No. 1-35, $1.52 \mathrm{~g}), \mathrm{D} 2$ (Fr. No. 36-49, $0.81 \mathrm{~g}$ ), D(3) (Fr. No. 50-88, 0.70 g), D(4) (Fr. No. 89-115, 0.53 g), D(5) (Fr. No. 116-130, 0.60 g), D(6) (Fr. No. 131-140, 0.52 g), D(7) (Fr. No. 141-205, 0.47 g), D(8) (Fr. No. 206-215, 0.51 g), D(9) (Fr. No. 216-220, 0.42 g), D(10) (Fr. No. 221-240, 0.40 g), D(11) (Fr. No. 241-250, 1.11 g) and D(12) (Fr. No. 251-313, $1.36 \mathrm{~g})$. Fraction $\mathrm{D}(6)$ was subjected to CC (230-400 mesh, $40 \mathrm{~g}$ ) eluted with $n$-hexane-EtOAc (3:1) to give an amorphous solid $\left(24.1 \mathrm{mg}\right.$ ) that was separated by HPLC (ODS, $75 \% \mathrm{MeOH}$, at $25{ }^{\circ} \mathrm{C}$, flow rate $4.0 \mathrm{~mL} \mathrm{~min}^{-1}, \mathrm{UV}=220 \mathrm{~nm}$, column $250 \times 20 \mathrm{~mm}$ i.d., $\left.5 \mu \mathrm{m}\right)$ to give Compounds $2(6.2 \mathrm{mg})$ and 3 (1.8 mg). Fraction D(8) was subjected to CC (230-400 mesh, $40 \mathrm{~g})$ eluted with $n$-hexane-EtOAc (3:1) to give an amorphous solid (34.0 mg), which was subsequently subjected to CC (230-400 mesh, $40 \mathrm{~g}$ ) eluted with $n$-hexane-EtOAc (3:1) to give an amorphous solid that was purified by HPLC (ODS, $75 \% \mathrm{MeOH}$, at $25^{\circ} \mathrm{C}$, flow rate $4.0 \mathrm{~mL} \cdot \mathrm{min}^{-1}, \mathrm{UV}=220 \mathrm{~nm}$, column $250 \times 20 \mathrm{~mm}$ i.d., $5 \mu \mathrm{m}$ ) to give Compounds 1 ( $7.50 \mathrm{mg}$ ) and 4 ( $3.8 \mathrm{mg})$. Fraction D(9) was subjected to CC (230-400 mesh, $30 \mathrm{~g})$ eluted with $n$-hexane-EtOAc $(3: 1)$ to give an amorphous solid $(25.5 \mathrm{mg})$, which was subsequently separated by HPLC (ODS, $70 \% \mathrm{MeOH}$, at $25^{\circ} \mathrm{C}$, flow rate $4.0 \mathrm{~mL} \cdot \mathrm{min}^{-1}$, UV $=220 \mathrm{~nm}$, column $250 \times 20 \mathrm{~mm}$ i.d., $5 \mu \mathrm{m}$ ) to give Compound 5 (6.3 mg).

\subsection{Analytical Data}

Compound 1: Colorless crystals; mp 83-85 ${ }^{\circ} \mathrm{C} ;[\alpha]_{D}^{25}+16.6^{\circ}$ (c 0.1, $\mathrm{CHCl}_{3}$ ); HRFABMS $m / z: 573.2719$ $[\mathrm{M}+\mathrm{H}]^{+}\left(\mathrm{C}_{31} \mathrm{H}_{41} \mathrm{O}_{10}\right.$, calcd for 573.2720); UV (EtOH) $\lambda_{\max } \mathrm{nm}(\log \varepsilon)$ : 230 (3.85); IR (KBr) $v_{\max } \mathrm{cm}^{-1}$; $3462(\mathrm{OH}), 2970,1727(\mathrm{O}-\mathrm{C}=\mathrm{O}), 1649(\mathrm{C}=\mathrm{C}-\mathrm{C}=\mathrm{O}), 1461 ;{ }^{1} \mathrm{H}$ - and ${ }^{13} \mathrm{C}-\mathrm{NMR}$, see Table 1 . FABMS $\mathrm{m} / \mathrm{z}$ (relative intensity (rel. int.)): $573\left([\mathrm{M}+\mathrm{H}]^{+}, 100\right), 555(11), 485(20)$.

Compound 2: Colorless crystals; $\mathrm{mp} 133-136{ }^{\circ} \mathrm{C} ;[\alpha]_{D}^{25}-18.1^{\circ}$ (c 0.1, EtOH); HRFABMS $m / z: 585.2701$ $[\mathrm{M}+\mathrm{H}]^{+}\left(\mathrm{C}_{32} \mathrm{H}_{41} \mathrm{O}_{10}\right.$, calcd for 585.2700); UV $\lambda_{\max }(\mathrm{EtOH}) \mathrm{nm}(\log \varepsilon)$ : 230 (4.11); IR (KBr) $\gamma_{\max } \mathrm{cm}^{-1}$ : $3537(\mathrm{OH}), 1748,1719 ;{ }^{1} \mathrm{H}$ - and ${ }^{13} \mathrm{C}-\mathrm{NMR}$, see Table 1 . FABMS $m / z$ (rel. int.): 607 (3) $[\mathrm{M}+\mathrm{Na}]^{+}$, $585(6),[\mathrm{M}+\mathrm{H}]^{+}, 567(6), 485(7), 83(100)$.

Compound 3: Colorless crystals; mp 181-184 ${ }^{\circ} \mathrm{C} ;[\alpha]_{D}^{25}-74^{\circ}$ (c 0.4, EtOH); HRFABMS $m / z: 683.2335$ $[\mathrm{M}+\mathrm{H}]^{+}\left(\mathrm{C}_{35} \mathrm{H}_{38} \mathrm{O}_{14}\right.$, calcd for 683.2340); UV $\lambda_{\max }(\mathrm{EtOH}) \mathrm{nm}(\log \varepsilon)$ : 226 (3.73); IR (KBr) $v_{\max } \mathrm{cm}^{-1}$ : 
1748, 1719; ${ }^{1} \mathrm{H}$ - and ${ }^{13} \mathrm{C}-\mathrm{NMR}$, see Table 1. FABMS $m / z$ (rel. int.): 683 (100) $[\mathrm{M}+\mathrm{H}]^{+}, 641$ (5), 586 (7), 507 (7), 95 (21).

Compound 4: Colorless crystals; mp 144-146 ${ }^{\circ} \mathrm{C} ;[\alpha]_{D}^{25}+43.3^{\circ}\left(c 0.1, \mathrm{CHCl}_{3}\right) ; \mathrm{HRFABMS} \mathrm{m} / z: 673.2492$ $[\mathrm{M}+\mathrm{H}]^{+}\left(\mathrm{C}_{34} \mathrm{H}_{41} \mathrm{O}_{14}\right.$, calcd for 673.2496); UV $\lambda_{\max }(\mathrm{EtOH}) \mathrm{nm}(\log \varepsilon)$ : 230 (3.73); IR (KBr) $\gamma_{\max } \mathrm{cm}^{-1}$ : $3657(\mathrm{OH}), 1728,1698 ;{ }^{1} \mathrm{H}$ - and ${ }^{13} \mathrm{C}-\mathrm{NMR}$, see Table 1 . FABMS $m / z$ (rel. int.): 695 (6) $[\mathrm{M}+\mathrm{Na}]^{+}$, $673(47)[\mathrm{M}+\mathrm{H}]^{+}, 613(10), 599(100)$.

Compound 5: Colorless amorphous; $[\alpha]_{D}^{25}-46.8^{\circ}\left(c\right.$ 0.1, $\left.\mathrm{CHCl}_{3}\right)$; HRFABMS $m / z: 791.2765[\mathrm{M}+\mathrm{H}]^{+}$ $\left(\mathrm{C}_{38} \mathrm{H}_{47} \mathrm{O}_{18}\right.$, calcd for 791.2763); UV $\lambda_{\max }(\mathrm{EtOH}) \mathrm{nm}(\log \varepsilon): 208$ (1.26), IR (KBr) $v_{\max } \mathrm{cm}^{-1}: 3352$ $(\mathrm{OH}), 1742(\mathrm{O}-\mathrm{C}=\mathrm{O}) ;{ }^{1} \mathrm{H}$ - and ${ }^{13} \mathrm{C}-\mathrm{NMR}$, see Table 2 . FABMS $m / z$ (rel. int.): $791[\mathrm{M}+\mathrm{H}]^{+}$(55), 735 (5), 95 (54), 43 (100), 329 (14), 176 (47).

\subsection{Determination of RAW264.7 Cell Proliferation}

RAW264.7 cell proliferation was examined according to a method reported previously [20] with few modifications. Briefly, RAW264.7 cells $\left(5 \times 10^{4}\right.$ cells in $\left.100 \mu \mathrm{L}\right)$ were seeded onto 96-well microplates and incubated for $24 \mathrm{~h}$. D-MEM $(100 \mu \mathrm{L})$ containing test samples (final concentration of $100,30,10$ or $3 \mu \mathrm{M}$ ) dissolved in DMSO (final concentration $0.2 \%$ ) was added. After the cells had been treated for $24 \mathrm{~h}$, the MTT solution was added. After $3 \mathrm{~h}$ of incubation, $20 \%$ sodium dodecyl sulfate (SDS) in $0.1 \mathrm{M} \mathrm{HCl}$ was added to dissolve the formazan produced by the cells. The absorbance of each well was read at $570 \mathrm{~nm}$ using a microplate reader. The optical density of vehicle control cells was assumed to be $100 \%$.

\subsection{Inhibitory Assay of NO Production}

An inhibitory assay of nitric oxide production was performed according to a method reported previously [16] with slight modifications. Briefly, RAW264.7 cells $\left(5 \times 10^{4}\right.$ cells in $\left.100 \mu \mathrm{L}\right)$ were seeded onto 96-well microplates and incubated for $24 \mathrm{~h}$. D-MEM $(100 \mu \mathrm{L})$ containing test samples (final concentration of 100, 30, 10 or $3 \mu \mathrm{M}$ ) dissolved in DMSO (final concentration $0.2 \%$ ) and LPS (final concentration of $5 \mu \mathrm{g} / \mathrm{mL}$ ) were added. After cells had been treated for $24 \mathrm{~h}, 50 \mu \mathrm{L}$ of $0.1 \%$ $N$-(1-naphtyl)ethylenediamine in $\mathrm{H}_{2} \mathrm{O}$ and $50 \mu \mathrm{L}$ of $1 \%$ sulfanilamide in $5 \%$ phosphoric acid were added. After being incubated for $30 \mathrm{~min}$, the absorbance of each well was read at $570 \mathrm{~nm}$ using a microplate reader. The optical density of vehicle control cells was assumed to be $100 \%$.

\section{Conclusions}

Two novel mexicanolide-type limonoids, carapanolides T-U (1-2), as well as three novel phragmalin-type limonoids, carapanolides V-X (3-5), were isolated from the seeds of Carapa guianensis (andiroba). Their structures were determined by spectroscopic analyses. Compounds $\mathbf{1}$ and $\mathbf{2}$ were mexicanolide-type limonoids that had $\mathrm{OH}$ in $\mathrm{C}-2$ and $\mathrm{C}-8$. Compounds 3-5 were phragmalin-type limonoids that were highly oxidized.

In the NO inhibitory assay, Compounds 1 and $\mathbf{2}$ exhibited similar NO inhibitory activities $\left(\mathrm{IC}_{50}\right.$ 1: $22.0 \mu \mathrm{M} ; 2$ : $23.3 \mu \mathrm{M}$ ) against L-NMMA ( $\mathrm{IC}_{50} 23.9 \mu \mathrm{M}$ ). Compound 1 did not exhibit cytotoxicity at 1-30 $\mu \mathrm{M}$, while Compound 2 exhibited low cytotoxicity at $30 \mu \mathrm{M}$, but not at an effective concentration at $10 \mu \mathrm{M}$. These results suggest that Compounds $\mathbf{1}$ and $\mathbf{2}$ have potential as anti-inflammatory disease agents.

Acknowledgments: We thank Mihoyo Fujitake (this university) for MS measurements.

Author Contributions: R. Tanaka prepared the manuscript. T. Miyake, S. Ishimoto, N. Ishimatsu and K. Higuchi contributed to the isolation and structure elucidation. K. Minoura conducted NMR measurement. T. Kikuchi performed evaluation of bioactivities. T. Yamada and O. Muraoka supervised whole research project.

Conflicts of Interest: The authors declare no conflict of interest. 


\section{References}

1. Tan, Q.G.; Luo, X.D. Meliaceous limonoids: Chemistry and biological activities. Chem. Rev. 2011, 111, 7437-7522. [CrossRef] [PubMed]

2. Fang, X.; Di, Y.T.; Hao, X.J. The advaces in the limonoid chemistry of the Meliaceae family. Curr. Org. Chem. 2011, 15, 1363-1391.

3. Liao, S.G.; Chen, H.D.; Yue, J.M. Plant orthoesters. Chem. Rev. 2009, 109, 1092-1140. [CrossRef] [PubMed]

4. Prophiro, J.S.; da Silva Mario, A.N.; Kanis, L.A.; da Rocha, L.C.B.P.; Duque-Luna, J.E.; da Silva, O.S. First report on susceptibility of wild Aedes aegypty (Diptera: Culicidae) using Carapa guianensis (Meliaceae) and Copaifera sp. (Leguminosae). Parasitol. Res. 2012, 110, 699-705. [CrossRef] [PubMed]

5. Penido, C.; Costa, K.A.; Pennaforte, R.J.; Costa, M.F.S.; Pereira, J.F.G.; Siani, A.C.; Henriques, M.G.M.O. Anti-allergic effects of natural tetranortriterpenoids isolated from Carapa guianensis Aublet onallergen-induced vascular permeability and hyperalgesia. Inflamm. Res. 2005, 54, 295-303. [CrossRef] [PubMed]

6. Nayak, B.S.; Kanhai, J.; Milne, D.M.; Pereira, L.P.; Swanston, W.H. Experimental Evaluation of Ethanolic Extract of Carapa guianensis L. Leaf for Its Wound Healing Activity Using Three Wound Models. Evid. Based Complement. Altern. Med. 2011, 2011. [CrossRef] [PubMed]

7. Penido, C.; Conte, F.P.; Chagas, M.S.S.; Rodrigue, C.A.B.; Pereira, J.F.G.; Henriques, M.G.M.O. Antiinflammatory effects of natural tetranortriterpenoids isolated from Carapa guianensis Aublet on zymosan-induced arthritis in mice. Inflamm. Res. 2006, 55, 457-464. [CrossRef] [PubMed]

8. Nayak, B.S.; Kanhai, J.; Milne, D.M.; Swanston, W.H.; Mayers, S.; Eversley, M.; Rao, A.V. Investigation of the wound healing activity of Carapa guianensis L. (Meliaceae) bark extract in rats using excision, incision, and dead space wound models. J. Med. Food. 2010, 13, 141-146. [CrossRef] [PubMed]

9. Bickii, J.; Njifutie, N.; Foyere, J.A.; Basco, L.K.; Ringwald, P.J. In vitro antimalarial activity of limonoids from Khaya grandifoliola C.D.C. (Meliaceae). J. Ethnopharmacol. 2000, 69, 27-33. [CrossRef]

10. Ferraris, F.K.; Rodrigues, R.; da Silva, V.P.; Figueiredo, R.; Penido, C.; Henriques, M.G.M.O. Modulation of $\mathrm{T}$ lymphocyte and eosinophil functions in vitro by natural tetranortriterpenoids isolated from Carapa guianensis Aublet. Int. Immunopharmacol. 2011, 11. [CrossRef] [PubMed]

11. Miranda, J.R.N.C.; Dolabela, M.F.; da Silva, M.N.; Povoa, M.M.; Maia, J.G.S. Antiplasmoidal activity of the andiroba (Carapa guianensis Aublet., Meliaceae) oil and its limonoid-rich fraction. J. Ethnopharmacol. 2012, 142, 679-683. [CrossRef] [PubMed]

12. Costa-Silva, H.; Lima, C.R.; Silva, E.J.R.; Araujo, A.V.; Fraga, M.C.C.R.; Ribeiro, E.; Ribwiro, A.; Arruda, A.C.; Lafayette, S.S.L.; Wanderley, J. Acute and subacute toxicity of the Carapa guianensis Aublet (Meliaceae) seed oil. J. Ethnopharmacol. 2008, 116, 495-500. [CrossRef] [PubMed]

13. Inoue, T.; Nagai, Y.; Mitooka, A.; Ujike, R.; Muraoka, O.; Yamada, T.; Tanaka, R. Carapanolides A and B: Unusual 9,10-seco-mexicanolides having a 2R,9S-oxygen bridge From the seeds of Carapa guianensis. Tetrahedron Lett. 2012, 53, 6685-6688. [CrossRef]

14. Inoue, T.; Matsui, Y.; Kikuchi, T.; In, Y.; Yamada, T.; Muraoka, O.; Matsunaga, S.; Tanaka, R. Guianolides A and B, New Carbon Skeletal Limonoids from the seeds of Carapa guianensis. Org. Lett. 2013, 15, 3018-3021. [CrossRef] [PubMed]

15. Inoue, T.; Matsui, Y.; Kikuchi, T.; In, Y.; Muraoka, O.; Yamada, T.; Tanaka, R. Carapanolides C-I from the seeds of andiroba (Carapa guianensis, Meliaceae). Fitoterapia 2014, 96, 56-64. [CrossRef] [PubMed]

16. Matsui, Y.; Kikuchi, T.; Inoue, T.; Muraoka, O.; Yamada, T.; Tanaka, R. Carapanolides J-L from the Seeds of Carapa guianensis (Andiroba) and Their Effects on LPS-Activated NO Production. Molecules 2014, 19, 17130-17140. [CrossRef] [PubMed]

17. Inoue, T.; Matsui, Y.; Kikuchi, T.; Yamada, T.; In, Y.; Muraoka, O.; Sakai, C.; Ninomiya, K.; Morikawa, T.; Tanaka, R. Carapanolides M-S from seeds of andiroba (Carapa guianensis, Meliaceae) and triglyceride metabolism-promoting activity in high glucose-pretreated HepG2 cells. Tetrahedron 2015, 71, 2753-2760. [CrossRef]

18. Zhang, Y.; Liu, C.; Dong, B.; Ma, X.; Hou, L.; Cao, X.; Wang, C. Anti-inflammatory Activity and Mechanism of Surfactin in Lipopolysaccharide-Activated Macrophages. Inflammation 2015, 38, 756-764. [CrossRef] [PubMed] 
19. Sakamoto, A.; Tanaka, Y.; Yamada, T.; Kikuchi, T.; Muraoka, O.; Ninomiya, K.; Morikawa, T.; Tanaka, R. Andirolides W-Y from the Flower Oil of Andiroba (Carapa guianensis, Meliaceae). Fitoterapia 2015, 100, 81-87. [CrossRef] [PubMed]

20. Yamada, T.; Muroga, Y.; Jinno, M.; Kajimoto, T.; Usami, Y.; Numata, A.; Tanaka, R. New class azaphilone produced by a marine fish-derived Chaetomium globosum. The stereochemistry and biological activities. Bioorg. Med. Chem. 2011, 19, 4106-4113. [CrossRef] [PubMed]

Sample Availability: Samples of the compounds are not available from the authors.

(C) 2015 by the authors; licensee MDPI, Basel, Switzerland. This article is an open access article distributed under the terms and conditions of the Creative Commons by Attribution (CC-BY) license (http:/ / creativecommons.org/licenses/by/4.0/). 